Elsevier

PAI 01394

\title{
The reflex sympathetic dystrophy syndrome associated with traumatic myelopathy: report of 5 cases
}

\author{
Steven A. Cremer *, Frederick Maynard ${ }^{* *}$ and Gary Davidoff $* *, * * *$ \\ * Department of Physical Medicine and Rehabilitation, University of Cincinnati School of Medicine, Cincinnati, OH (U.S.A.), \\ ** Department of Physical Medicine and Rehabilitation, University of Michigan Medical Center, Ann Arbor, MI (U.S.A.), \\ and *** Rehabilitation Medicine Service, Veterans Administration Medical Center, Ann Arbor, MI (U.S.A.)
}

(Received 21 September 1988, revision received and accepted 29 November 1988)

\begin{abstract}
Summary Pain is a frequent problem following recent traumatic spinal cord injury (SCI). Of specific concern in the rehabilitation setting is function-limiting hand pain which prevents optimal participation in therapy and limits independence. A treatable etiology of function-limiting hand pain in SCI is the reflex sympathetic dystrophy syndrome (RSDS). The presentation of RSDS in patients with recent SCI can be easily confused with that of dysesthetic (central origin) or radicular pain. Previous reports of RSDS associated with recent traumatic SCI have not been based on specific clinical criteria outlined in recent literature, and treatment has not been evaluated by objective outcome measures. This report describes 5 cases of RSDS associated with recent traumatic SCI that are identified by specific clinical criteria and are confirmed by a 3 phase hone scan. It is suggested that aggressive early intervention is necessary to obtain optimal functional outcome and minimize length of hospital-based rehabilitation.
\end{abstract}

Key words: Pain; Reflex sympathetic dystrophy; Spinal cord injury

\section{Introduction}

Pain ia a frequent complication of traumatic spinal cord injury (SCI) and reported incidence estimates range from 11 to $94 \%[3,4,7,9-12,21-23]$. These studies of pain following SCI are difficult to compare due to problems associated with classification of pain syndromes. A specific concern during rehabilitation is pain which limits optimal participation in therapy and achievement of selfcare goals. Estimates of function limiting pain associated with SCI vary from 11 to $34 \%[3,9,11$, $21,24]$. Radicular or dysesthetic (central origin) pain at or below the level of the zone of injury is

Correspondence to: Gary Davidoff, M.D., M.S., Dept. of PM\&R, 1D204 Univ. Hospital, 0042, 1500 East Medical Center Drive, Ann Arbor, MI 48109-0042, U.S.A. felt to be among the most common of the debilitating pain syndromes [7,10,24]. A less common cause of diffuse upper extremity pain associated with recent SCI is the reflex sympathetic dystrophy syndrome (RSDS). Distal upper extremity edema, trophic skin changes, loss of active range of motion (ROM) and hyperesthesia are associated with RSDS and can severely limit functional ability.

In the last decade, clinical diagnostic criteria for RSDS have been proposed by Kozin and associates [14-16]. The criteria they offered describe four levels of clinical suspicion for RSDS based on the presence or absence of distal limb pain, distal limb edema and vasomotor instability (e.g., hyperhydrosis, decreased skin temperature). Additionally, the 3 phase technetium bone scan (TPBS) has been shown to be useful as an adjunct to the diagnosis of RSDS [8,16-19,27,30]. Objec- 
live measures for treatment efficacy have recently been introduced for RSDS and include measurement of active range of motion, limb volume, joint pain index and skin temperature [6].

This report describes five cases of RSDS associated with recent traumatic SCI and confirmed by TPBS. In individual cases, objective measures were obtained before and after treatment.

\section{Methods}

All patients in the report were admitted following acute SCI to the University of Michigan Model Spinal Cord Injury Care System between December, 1985 and February, 1987. Patient ages ranged from 23 to 55 years. Specific information concerning gender, level and completeness of injury, etiology, medical management and time to onset of pain post-injury is described in Table I. All patients met the Kozin criteria for definite RSDS (diffuse distal limb pain, distal limb edema and vasomotor instability) or probable RSDS (diffuse distal limb pain and either distal limb edema or vasomotor instability). Objective measurements of distal joint pain, limb volume, and active digit range of motion as described by Davidoff et al. [6] were obtained in individual cases at initiation of treatment and 8 weeks later. Grip strength was obtained simultaneously. Prior to treatment all patients underwent a TPBS following injection of $15 \mathrm{mCi}$ of technetium- $99 \mathrm{~m}$ methylenediphosphonate, and results were interpreted using estab- lished criteria [14-16,19]. All patients demonstrated diffusely increased radionuclide activity in the $3 \mathrm{~h}$ delayed images, consistent with the findings noted in the RSDS [14-17,19].

\section{Results}

Case I. A 55-year-old white female sustained a gunshot wound to the neck resulting in tracheal and esophageal lacerations, a $\mathrm{C} 7$ vertebral body fracture and a right $\mathrm{C} 8$, left $\mathrm{T} 1$ sensory and motor complete quadriplegia. Upper extremity active range of motion was full and pain free during initial care. At 4 weeks post-injury, 2 days before transfer to the rehabilitation unit, she developed severe right shoulder pain with limited active and passive range of motion, tenderness to palpation of the MCP and IP joints and right hand edema. The patient was treated with aggressive passive range of motion exercise and analgesics for 2 weeks without improvement. A rapid burst and taper of oral prednisone was given over a 2 week period. Hand volume and distal joint pain measures decreased, while grip strength and active range of motion of the hand improved over the treatment period (Fig. 1). Full pain-free AROM of the shoulder was restored. Upper extremity pain and tenderness was resolved 1 month after initiation of treatment. Follow-up 6 months after treatment revealed no recurrence of symptoms and a normal TPBS study.

TABLE I

PATIENT CHARACTERISTICS

\begin{tabular}{|c|c|c|c|c|c|c|}
\hline Case & Age/sex & Level & Etiology & $\begin{array}{l}\text { Time of onset of } \\
\text { pain from injury } \\
\text { (months) }\end{array}$ & $\begin{array}{l}\text { Laterality } \\
\text { of pain }\end{array}$ & $\begin{array}{l}\text { Surgical } \\
\text { stabilization }\end{array}$ \\
\hline I & $55 / \mathrm{f}$ & $\mathrm{C} 8 *$ & Gunshot & 1 & Bilateral & No \\
\hline II & $27 / \mathrm{m}$ & $\mathrm{C} 6^{*}$ & Gunshot & 1 & Right & No \\
\hline III & $53 / \mathrm{m}$ & $\mathrm{C} 6^{* *}$ & $\begin{array}{c}\text { Motoreycle } \\
\text { accident }\end{array}$ & Immediate & Bilateral & No \\
\hline IV & $27 / \mathrm{m}$ & $\mathrm{C} 5^{*}$ & Fall & Immediate & Bilateral & Yes \\
\hline $\mathrm{V}$ & $50 / \mathrm{f}$ & $\mathrm{C} 8 * *$ & Fall & 3 & Right & No \\
\hline
\end{tabular}

* Denotes complete SCI.

* Denotes incomplete SCI. 

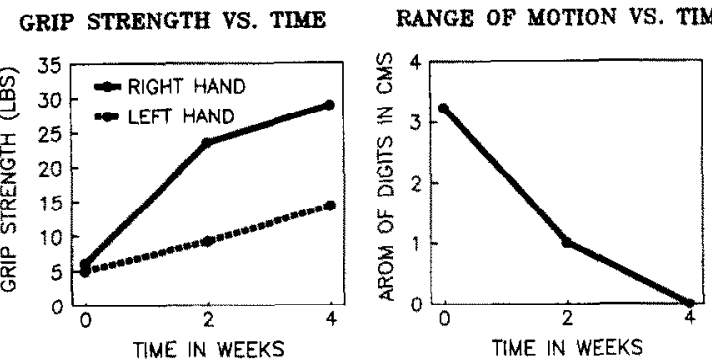

JOINT PAIN VS. TIME
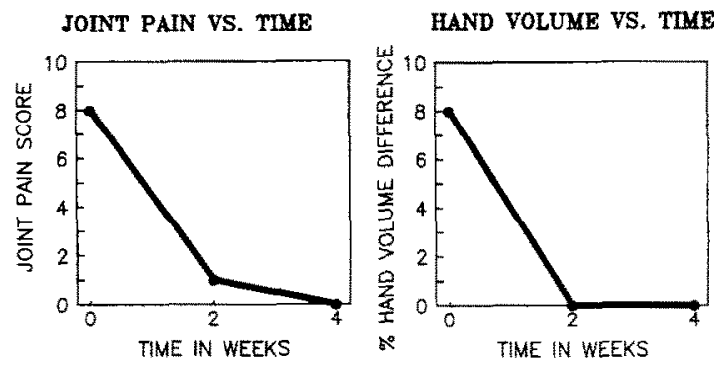

Fig. 1. Pain and function measures before and during treatment of case I for reflex sympathetic dystrophy.

Case II. A 27-year-old black male suffered a C7 comminuted fracture and $\mathrm{C} 6$ motor and sensory complete quadriplegia secondary to a gunshot wound. One month after surgical repair of soft tissue injuries the patient developed slow onset of bilateral severe burning pain along the radial aspects of both forearms and the first 2 digits. Poorly controlled by propoxyphene or acetaminophen, the pain prevented any functional activities during acute care hospitalization. Six weeks postinjury the patient was transferred to the rehabilitation unit, where evaluation revealed severely limited and painful passive range of motion at the shoulders, elbows, wrists and fingers, without bony block. Non-pitting edema and atrophic skin of the hands and digits were noted. Severe hyperesthesia with tactile defensiveness was found in both distal upper extremities. Initial differential diagnosis was dysesthetic pain at the zone of injury vs. RSDS. Hand radiographs revealed diffuse demineralization of the MCP and IP joints bilaterally. Aggressive medical intervention with corticosteroids was felt to be contraindicated due to a history of sepsis. Sympathetic blockade was refused by the patient. Treatment of upper extremity pain and contractures were a major rehabilitation team focus during the following 14 weeks of hospitaliza- tion, and included frequent passive range of motion stretching, tactile desensitization, splinting, serial casting and transcutaneous nerve stimulation. At discharge, pain and PROM were improved, but continued to be severe enough to interfere with achievement of functional goals. Follow-up 12 months later found pain complaints, limitations in PROM and functional activities unchanged.

Case III. A 53-year-old white male sustained head, face and neck injuries (cervical hyperextension) in a motorcycle accident, mild $(4 / 5)$ bilateral weakness of grip and intrinsic hand muscles, as well as minimal sensory impairment in lower cervical dermatomes, suggesting a C6 incomplete spinal injury. Recovery of motor and sensory deficits. improved with non-surgical management. During a 1 week hospitalization, he became independent in ambulation and self care, although he continued to complain of hand pain. At SCI clinic follow-up 10 weeks after injury, he reported burning pain in digits 4 and 5 and in the medial forearms, as well as finger stiffness and hand weakness. Examination revealed mild grip and intrinsic muscle weakness, sensory loss, decreased AROM, tenderness of the IP joints of digits 4 and 5 and mild edema of the hand. No trophic changes were noted. Electrodiagnostic studies were negative for compressive mononeuropathy affecting the upper extremities (e.g., tardy ulnar palsy). An out-patient therapy program involving aggressive AROM, desensitization and moist heat for 2 months improved, but did not resolve, his symptoms. A rapid burst and taper of oral corticosteroids was given. Although the patient reported improvement in subjective complaints, objective measures failed to show improvement. Three months after the steroid burst, symptoms had improved sufficiently to allow the patient to return to full-time employment.

Case IV. A 32-year-old white male sustained cervical fracture at $\mathrm{C} 4,5$ and $\mathrm{C} 5,6$ with a $\mathrm{C} 6$ fracture-dislocation as a result of a $12 \mathrm{ft}$ fall. Within $24 \mathrm{~h}$ he complained of diffuse bilateral upper extremity pain and developed increasing tactile defensiveness. These abnormalities persisted during acute care, in spite of frequent PROM and splinting. Following cervical fusion and halo- 
vest cervical immobilization, he was transferred to the rehabilitation unit at 5 weeks post-injury. At that time, he showed sensory and motor incomplete $\mathrm{C} 8$ quadriplegia, bilateral edema of the hands, MCP and IP tenderness, and limitations in AROM of the digits secondary to pain. A rapid burst and taper of corticosteroids was initiated in coordination with desensitization techniques and aggressive AROM exercises. A decrease in objective findings and subjective complaints was noted by the third day of intervention. His rehabilitation program then followed an unremarkable course. No recurrence of pain was noted during 6 months of follow-up care.

Case $V$. A 50-year-old white female with spastic quadriplegia and dystonia secondary to cerebral palsy, sustained a cervical hyperextension injury during a transfer, associated with the onset of flaccid $\mathrm{C} 8$ sensory-motor incomplete quadriplegia. She regained pre-injury spastic motor control of the lower extremities during 3 weeks of inpatient hospitalization, but continued to have persistent weakness of the upper extremities at discharge to her group home. At SCI clinic follow-up 3 months post-injury, she complained of right shoulder and hand pain. Examination revealed pitting edema of the right hand, periarticular and MCP pain on palpation, and limited AROM of the shoulder secondary to pain. Symptoms improved with an AROM program and nonsteroidal anti-inflammatory agents over the following 3 months.

\section{Discussion}

Proper diagnosis of the RSDS in traumatic SCI identifies a treatable etiology of function-limiting pain which retards rehabilitation progress and impairs independence. Medical management of the RSDS varies from that of dysesthetic (central origin) or radicular pain. Since treatment with corticosteroids or regional/peripheral sympathetic blockade is not without risk, reasonable certainty of diagnosis is desired $[2,13,16,20]$. Likewise, dorsal root entry zone ablation, which has possible utility in the management of severe radicular SCI pain, would be totally inappropriate as part of the treatment program for the RSDS [23].
Therefore, development of specific criteria for diagnosis of and objective measures for outcome are essential. The patients in this series showed characteristic signs which differed from those noted in patients with dysesthetic (central origin) or radicular pain. Radicular pain following $\mathrm{SCI}$ occurs in a distinctive dermatomal or nerve root distribution at the zone of injury [10]. Dysesthetic pain can easily be confused with RSDS, since both diffuse burning pain and tactile defensiveness may be seen at or below the zone of injury [7,10]. Davidoff et al. [7] noted several characteristics commonly found among patients with dysesthetic pain including incomplete sensory injuries, increased incidence among paraplegics, penetrating wounds to the spinal cord, and conservative management of the spine fractures. In this study, all patients had $\mathrm{C} 6, \mathrm{C} 7$ or $\mathrm{C} 8$ quadriplegia. Two spinal injuries were associated with gunshot wounds, and 2 patients had incomplete central cord syndromes. Patients in both groups were usually managed with non-operative immobilization, rather than surgical stabilization. In both dysesthetic pain and RSDS patient groups, onset occurred within the first year of injury. It would appear that level, etiology, completeness of injury and type of management of the spinal fracture do not differentiate between patients who develop dysesthetic pain or the RSDS.

Previous reports of RSDS associated with SCI have been based primarily on physical examination and included no objective measures for clinical findings or treatment outcome. Ohry [25] describes 2 cases of 'shoulder hand syndrome,' a subset of RSDS, in a series of quadriplegic patients with shoulder pain. Andrews and Armitage [1] reported that 4 of 19 quadriplegic patients with hand pain had radiologic evidence of Sudek's atrophy, a roentgenologic finding associated with the later stages of $\operatorname{RSDS}[17]$. Wainapel $[28,29]$ reported 2 cases of recent quadriplegia with the RSDS, 1 of which had documentation of abnormal skin temperatures and hyperhydrosis requiring therapeutic intervention for suspected RSDS.

None of these reports used standardized criteria for the clinical diagnosis of the RSDS, such as those proposed by Kozin [16]. Measures of hand volume, grip strength, joint tenderness and AROM 
of the hands, as detailed in case I, allowed for documentation of findings and response to treatment in this study [6]. Incidence data was not discussed in this report, since the study described patients who were referred for inpatient rehabilitation, rather than all patients with a traumatic myelopathy.

The TPBS can be a useful adjunct to diagnosis. Patients with dysesthetic (central) or radicular pain would be expected to have a normal TPBS, whereas patients with definite or probable RSDS are likely to demonstrate diffusely increased activity in the blood flow, blood pool and delayed uptake images $[7,17,30]$. Recent studies indicate that the TPBS has a markedly decreased predictive value in the diagnosis of RSDS when performed more than 6 months after onset of symptoms, or in patients $<50$ years [30]. This may explain why all patients in this study had an abnormal TPBS, as compared to $50 \%$ of our previous series of RSDS patients.

While the RSDS is an infrequent cause of functionally limiting pain in patients with recent traumatic SCI, early diagnosis and treatment are critical to a successful outcome. The TPBS can help to differentiate this disorder from that of dysesthetic (central origin) or radicular pain. By using easily quantifiable and reproducible measures of clinical signs, treatment outcome can be objectively measured [6].

\section{Acknowledgements}

This work was supported by a Clinical Investigator Development Award to Prof. Davidoff from the National Institute of Neurologic and Communicative Disorders and Stroke, Bethesda, Maryland (NS-01120-03), and a Model Systems Spinal Cord Injury Grant from the National Institute on Disability and Rehabilitation Research (G-008535130).

\section{References}

1 Andrews, L.G. and Armitage, K.J., Sudek's atrophy in traumatic quadriplegia, Paraplegia, 9 (1971) 159-165.

2 Bonelli, S., Conoscente, F. and Movilla, P.G., Regional intravenous guanethidine vs. stellate ganglion block in re- flex sympathetic dystrophies: a randomized trial, Pain, 16 (1983) 297-307.

3 Botterell, E.H., Callaghan, J.C. and Joussi, A.T., Pain in paraplegia, clinical management and surgical treatment, Prof. R. Soc. Med., 47 (1953) 281-288.

4 Burke, D.C., Pain in paraplegia, Paraplegia, 10 (1973) 297-313.

5 Christensen, K., Jensen, E.M. and Noer, 1., The reflex sympathetic dystrophy syndrome response to treatment with systemic corticosteroids, Acta Chir. Scand., 148 (1982) 653-655.

6 Davidoff, G., Morey, K., Amann, M. and Stamps, J., Pain measurement in reflex sympathetic dystrophy syndrome, Pain, 32 (1988) 27-34.

7 Davidoff, G., Roth, E., Guarracini, M., Sliwa, J. and Yarkony, G., Functional-limiting dysesthetic pain syndrome among traumatic spinal cord injury patients: a cross-sectional study, Pain, 29 (1987) 39-48.

8 Davidoff, G., Werner, R., Cremer, S.A., Jackson, D., Ventocilla, $C$. and Wolf, L., The predictive value of the three phase bone scan in the diagnosis of the reflex sympathetic dystrophy syndrome, Arch. Phys. Med. Rehabil., 70 (1989) 135-137.

9 Davis, L. and Martin, J., Studies upon spinal cord injuries. II. The nature and treatment of pain, J. Neurosurg., 4 (1947) 483-491.

10 Donovan, W.H., Dimitrijevic, M.R, Dahm, L. and Dimitrijevic, M., Neurophysiological approaches to chronic pain following spinal cord injury, Paraplegia, 20 (1982) $135-146$.

11 Kaplan, L.I., Grynbaum, B.B., Floyd, K.E. and Rusk, H.A., Pain and spasticity in patients with spinal cord dysfunction: results of a follow-up study, J.A.M.A., 182 (1962) 918-925.

12 Kennedy, R.H., The new viewpoint toward spinal cord injuries, Ann. Surg., 124 (1946) 1057-1065.

13 Kleinert, H.E., Cole, N.M., Wayne, L., Harvey, R., Kutz, J.E. and Atasoy, E., Post-traumatic sympathetic dystrophy, Orthop. Clin. N. Am., 4 (1973) 917-927.

14 Kozin, F., Genant, H.K., Bekerman, C. and McCarthy, D.J. The reflex sympathetic dystrophy syndrome. II. Roentgenographic and scintigraphic evidence of bilaterality and of periarticular accentuation, Am. J. Med., 60 (1976) $332-338$.

15 Kozin, F., McCarty, D.J., Sims, J. and Genant, H.K., The reflex sympathetic dystrophy syndrome. I. Clinical and histologic studies: evidence of bilaterality, accentuation of periarticular regions and predictable response to corticosteroids, Am. J. Med., 60 (1976) 321-331.

16 Koxin, F., Ryan, L.L.M., Carerra, G.F., Soin, J.S. and Wortmann, R.L., The reflex sympathetic dystrophy syndrome (RSDS). III. Scintigraphic studies, further evidence for the therapeutic efficacy of systemic corticosteroids and proposed diagnostic criteria, Am. J. Med., 70 (1981) 23-30.

17 Kozin, F., Soin, J.S., Ryan, L.M., Carrera, G.F. and Wortmann, R.L., Bone scintigraphy in the reflex sympathetic dystrophy syndrome, Radiology, 138 (1981) 437-443.

18 Mackinnon, S.E. and Holder, L.E., The use of three phase 
radionuclide bone scanning in the diagnosis of reflex sympathetic dystrophy, J. Hand Surg. [Am], 9A (1984) 556-562.

19 Maurer, A.H., Holder, L.E., Espinola, D.A., Rupani, H.D. and Wilgus, E.F., Three phase scintigraphy of the hand, Radiology, 146 (1983) 761-775.

20 Mowat, A.G., Treatment of shoulder hand syndrome with corticosteroids, Ann. Rheum. Dis., 33 (1974) 120-123.

21 Munro, D., Rehabilitation of veterans paralyzed as the result of injury to the spinal cord and cauda equina, Am. J. Surg., 75 (1948) 3-17.

22 Munro, D., Two-year end-results in the total rehabilitation of veterans with spinal-cord and cauda equina injuries, New Engl. J. Med., 242 (1950) 1-10.

23 Nashold, B.S. and Bullitt, E., Dorsal-root entry zone lesions to control central pain in paraplegics, J. Neurosurg., 55 (1981) 414-419.

24 Nepomuceno, C., Fine, P.R., Richards, J.S., Gowens, H., Stover, S.L., Rantanuabol, U. and Houston, R., Pain in patients with spinal cord injury, Arch. Phys. Med. Rehabil., 60 (1979) 605-609.
25 Ohry, A., Brooks, M.E., Steinbach, T.V. and Rozin, R. Shoulder complications as a cause of delay in rehabilitation of spinal cord injured patients, Paraplegia, 16 (1978) $310-316$.

26 Schutzer, S.F. and Gossling, H.R., Current concepts review: the treatment of reflex sympathetic dystrophy syndrome, J. Bone Joint Surg. [Am], 66A (1984) 625-629.

27 Tepperman, P.S., Greyson, N.D., Hilbert, L., Jimenez, J. and Williams, J.I., Reflex sympathetic dystrophy in hemiplegia, Arch. Phys. Med. Rehabil., 65 (1984) 442-446.

28 Wainapel, S.F. and Freed, M.M., Reflex sympathetic dystrophy in quadriplegia: case report, Arch. Phys. Med. Rehabil., 65 (1984) 35-36.

29 Wainapel, S.F., Reflex sympathetic dystrophy following traumatic myelopathy, Pain, 18 (1984) 345-349.

30 Werner, R., Davidoff, G., Jackson, M.D., Cremer, S. Ventocilla, C. and Wolf, L., Factors affecting the sensitivity and specificity of the three phase technetium bone scan in the diagnosis of reflex sympathetic dystrophy in the upper extremity, J. Hand Surg. [Am], (1988) in press. 